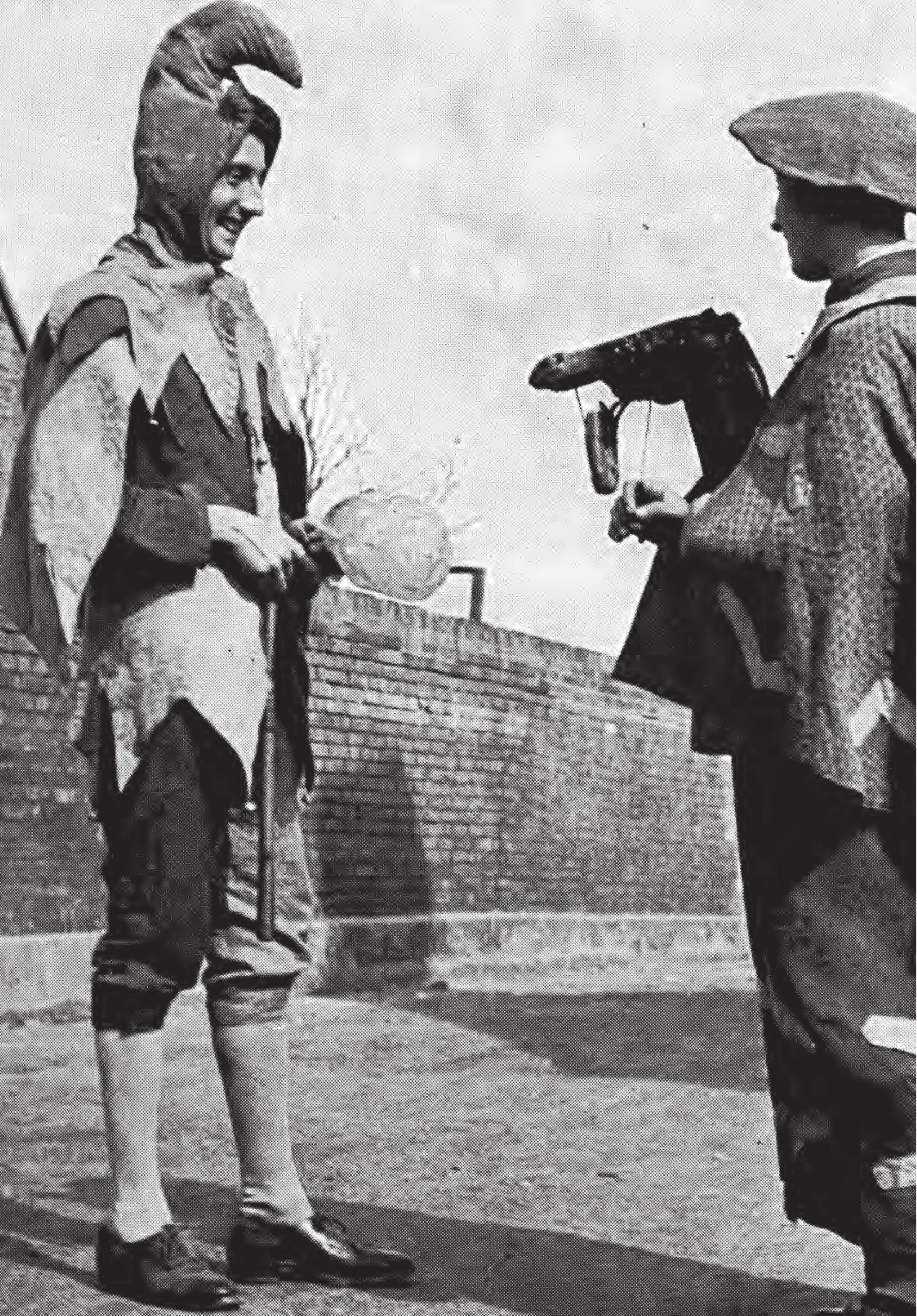




\section{COMENTÁRIOS \\ De um filósofo municipal, que, depois de comentado, pode ser promovido a filósofo estadual}

JosÉ ARTHUR GIANNOTTI

\section{A Luiz Henrique dos Santos}

Como sempre Luiz Henrique torna preciso o que estou pensando, alinha minha maneira errática de refletir. Wittgenstein me tem apresentado intuições e instrumentos, não argumentos, para pensar minhas manias. Mas essa "instrumentalização" sempre caminha em dois sentidos: de um lado, me leva a entender melhor seus textos e suas intenções, de outro me empurra para as margens de certos temas caros ao filósofo, em particular tudo o que escreveu sobre moral e não escreveu sobre política. Não há interpretação neutra de um texto filosófico. Filosofar é trabalhar diferenças, levando em conta também a grandeza e o alcance de cada trabalho - o meu municipal, o dele internacional. Muito me incomoda citar uma frase solta de um grande filósofo para legitimar posições. O que legitima cada trabalho é o desenho ambíguo de seu próprio movimento. O texto de Luiz Henrique deixa no horizonte um grande problema: qual é a historicidade dos jogos de linguagem? Quem sabe se ainda terei tempo para estudá-lo.

\section{ARúrion Melo}

Devo agradecer a Rúrion a excelente apresentação dos meus primeiros estudos de Marx, o que ajuda a explicitar minhas complexas relações com o marxismo. Se a teoria do valor trabalho não vale como instrumento científico, não é por isso que não serve para indicar o sentido das relações capitalistas. Denuncia um de seus aspectos importantes, seu caráter alienado: tudo se passa como se o capital, a terra e o salário produzissem naturalmente lucro e juros, renda da terra e salário. Como relações humanas podem aparecer como se fossem relações naturais? 
No entanto, ao contrário do que esperava Marx, o modo capitalista de produção, ao se tornar cada vez mais complexo, não se configura como a contradição entre capital e trabalho, alimentada pela tendência à queda da taxa de lucro. São tantos os fatores incidentais que a própria reposição do sistema fica na dependência de políticas reparadoras. Sem políticas públicas, nacionais ou regionais, a economia capitalista não anda. Desaparece, então, aquele corte que Hegel apontou entre a sociedade civil e o Estado. A trama de relações meramente socioeconômicas é permeada pela demanda de cada uma de suas partes pela luta por seus direitos, vale dizer, o direito de participar de uma economia capitalista bem planejada e sem crises. A política, antes de ser o combate dos interesses de aliados e adversários, passa a depender da reparação do silogismo econômico, da continuidade do capital como um todo. O Estado se torna o guardião do capital, em particular do capital variável, isto é, dos trabalhadores. Por isso a eficácia e a relativa justiça dessa guarda dependem do jogo democrático, da expressão e do exercício de vários pontos de vista.

\section{AMarcos Nobre}

O projeto de uma teoria geral da ilusão necessária me parece totalmente fora de propósito. No fundo essa ilusão se arma quando tudo se passa como se uma mera representação, por si mesma, passasse a dar realidade ao representado. Na teoria dos conjuntos esse tipo de ilusão aparece no axioma da escolha: existe um conjunto formado pelos representantes de todos os outros conjuntos? Como não se dá o método pelo qual se escolhem esses representantes, a existência do conjunto é postulada antes de seus elementos serem captados. É como se, nos lembra Bertrand Russell, afirmássemos que existe o número formado pelos dígitos a serem escolhidos numa máquina de calcular, antes de eles serem teclados. Essa existência representada parece legítima em matemática, a despeito das críticas quelhe fazem os intuicionistas. Do mesmo modo, o funcionamento das neuroses descrito por Freud implica o enrijecimento de comportamentos ilusórios. No caso do sistema capitalista de produção, ela se dá na instituição da mercadoria, que, para se instalar como valor-trabalho, precisa se dar como se ela fosse trocável por qualquer outra mercadoria que viesse ao mercado. Em suma, a ilusão necessária funciona diferentemente em cada sistema particular, requerendo, portanto, uma análise peculiar de como funciona em cada um deles.

A meu ver, reclamar uma teoria geral da ilusão necessária é continuar prestando homenagem à ideia clássica de razão. Ora, tentei mostrar que a crise dos fundamentos da aritmética nasce porque novos conceitos - grupo, número e todo sistema axiomático em geral 
— não podem funcionar como predicados que determinam o objeto nomeado pelo sujeito. É toda a estrutura que se aplica ao real. Isso faz com que a relação entre a forma e seus conteúdos não se esgote numa mera predicação. Por isso, "comparação de um conceito com o conteúdo em vista de sua verdade (atual ou potencial)", no dizer de Adorno, citado por Marcos, retoma o sentido da predicação, embora procure destruir a identidade conceitual que marca as próprias coisas.Antes de tentar a recuperação do projeto iluminista, cabe, então, iluminá-lo a partir de uma reflexão sobre a ideia de razão. Para isso é preciso refletir como essas "formas" se reportam ao real. A dialética negativa toma o conceito como uma espécie de carimbo marcando esse real para examinar as sobras que escapam dessa marcação. A teoria da ação comunicativa divide a proposição em duas partes, conteúdo proposicional e posição. Ambas as tentativas ficam aquém dos métodos estruturantes das novas matemáticas.

De novo, pedir uma teoria geral da posição (Setzung) me parece um projeto metafísico impossível de ser logicamente elaborado. Existe posição no silogismo aristotélico. Ela penetra no seio da proposição com o psicologismo inaugurado pela filosofia moderna e se configura claramente em Kant quando este "corrige" a definição formal do juízo, demandando que a união do sujeito e do predicado seja remetida à atividade ponente do sujeito transcendental. Em Hegel, por sua vez, a proposição declarativa se desfaz numa contradição, mas o conceito continua a determinar como se fosse um predicado que, encontrando resistência, se volta sobre si mesmo. A reflexão, que já em Kant entra em cena nos juízos reflexionantes, passa a ser a semente da dialética hegeliana. Mas uma reflexão que sempre tem por trás a unicidade fechada do eu transcendental ou do Espírito absoluto. No entanto, encontramos na vida cotidiana reflexões sem posição proposicional. Ao medir com um metro um comprimento, a manutenção prática dessa unidade padrão depende do intervalo de erros admissível. O metro não serve para medir distâncias estelares, embora estas, depois de calculadas, possam ser reduzidas a expressões métricas.

No fundo, é psicologismo pensar a estrutura da proposição declarativa necessariamente como uma posição. Apimentá-lo com um traço transcendental não muda o fato de que este não provém de uma análise do funcionamento das proposições. O psicologismo transcendental de Kant e o Espírito Absoluto de Hegel são máquinas ponentes. Mas na lógica de hoje a posição (Setzung) se resume a um dos procedimentos para construir certos sistemas simbólicos, ela não participa necessariamente da intencionalidade de suas estruturas. Marcos percebe que sem posição não há Teoria Crítica, mas cabe aos teóricos críticos mostrar que a ponência de uma proposição não lhe 
advém simplesmente do jogo da bi e da monopolaridade. Inventaram o monstro e que saibam cuidar dele.

Não ignoro a importância do sujeito na filosofia ocidental, mas a perspectiva pela qual a estudei não passa necessariamente pelo sujeito fundante. E outras linhas são igualmente possíveis. Isso não significa que despreze a importância desse sujeito na vida de hoje, nem que não veja o impulso renovador, embora também conservador, da subjetividade contemporânea. O que para mim está fora de questão é pensar a crítica da modernidade a partir de um ponto de vista privilegiado que negue a irredutibilidade do outro. Isso tem consequências que não são apenas teóricas.

Do ponto de vista da dobradiça lógica-ontologia, importa pois a quebra do privilégio que teve a proposição apofântica na construção dos sistemas "lógicos". Daí a importância da dupla Heidegger e Wittgenstein, o primeiro porque, antes da proposição, encontra o ser que se abre para o ente; o segundo porque, num jogo de linguagem, cada regra passa a ser vista como uma "proposição" no que ela tem de mais essencial, a saber, o balanço da bipolaridade do verdadeiro e do falso. Isso inclusive para jogos de linguagem não verbais, como um sistema de setas a indicar comportamentos corretos e incorretos. Além disso, a bipolaridade somente funciona em contraste com a monopolaridade das expressões de uma forma de vida.

O abandono da posição, por conseguinte do primado da reflexão dual entre um sujeito e um predicado, não implica, de modo nenhum, o abandono da procura sistemática dos a priori práticos, e implica menos ainda privilégio da teoria sobre a prática. O estudo do contraponto entre Heidegger e Wittgenstein vai nesse sentido, já que ambos são filósofos "práticos", onde o "uso" está entranhado no sentido. Mas seria tolice de minha parte tentar me apropriar da ontologia heideggeriana - aliás, somente proposta antes da reviravolta, da Kehre, por que passa Heidegger depois da publicação de Ser e tempo — para combiná-la com a lógica da linguagem de Wittgenstein. Como este afirma explicitamente, a ontologia está na linguagem, e, como não existe "a linguagem”, todas as ontologias são regionais. É desse lado que bate meu coração, e, se passo detalhadamente por Heidegger, é para refazer a gênese da significação feita em Ser e tempo. Análise que começa a ser feita quando Heidegger examina o funcionamento daquela seta usada nos carros para indicar direção. A base da significância reside na diferença ontológica entre sere ente. Em contrapartida, para Wittgenstein, esse jogo de linguagem não verbal se instalaria pelo jogo das ações ditas adequadas e inadequadas à nova situação. Isso me leva a duvidar da noção heideggeriana de fenômeno como algo que se dá ao mesmo tempo que seesconde. O que me importaé delinear os limites da noção de algo e de fenômeno. Todas essas diferenciações me levam a separar 
radicalmente o conceito de mundo da vida (Heidegger) e imagem de mundo (Wittgenstein), o pano de fundo situando as ações humanas. "Colonizar o mundo da vida" só pode ter um sentido fenomenológico, mas é um disparate do ponto de vista dos jogos de linguagem.

Reconheço, pois, a necessidade do estudo de ontologias regionais segundo os sistemas linguísticos que as ordenam. Não me identifico de modo algum com a crítica heideggeriana da modernidade, baseada numa crítica da tecnociência, que deixa de ser Setzung para ser Gestell, armação. Pelo contrário, ao sublinhar que a crítica da modernidade ainda deve ser feita a partir das alienações do capital - como explicitei em Certa herança marxista -, estou deixando de lado qualquer crítica que se monte a partir de uma crítica da razão, em particular da crítica da razão vinculada a fins. Não é por isso que a crítica esquerdista dos frankfurtianos em grande parte reproduz a crítica da direita alemã, cujo maior representante é precisamente Heidegger? Não é porque Gestellé substituído por Setzung que essa crítica muda de sentido. Ambos se apavoram diante dos poderes da tecnociência, quando o problema me parece estar na utilização política dessa extraordinária força produtiva. Daí a importância da democracia, que já se encontra in nuce na luta entre os capitais para encontrar posições estratégicas no mercado. Mais do que o fetichismo da mercadoria, que pressupõe apenas uma forma social de propriedade privada, me interessa a alienação do capital. Esta é estudada por Marx no terceiro volume de seu livro máximo sob a forma trinitária que assume o capital: o capital investido produz naturalmentelucro ejuros, a propriedade fundiária, renda, eo trabalho, salário. Nessa alienação reside a necessidade de reconhecer tanto a validade do outro como do autoritarismo como forma segura de combater a crise dessa estrutura quando seus pressupostos encontram dificuldade de serem repostos. Se a democracia atual dos países em crise fosse aprofundada, se os desempregados pudessem fazer valer seus interesses, seria possível que essa crise, que se inicia com a crise do sistema financeiro, fosse superada simplesmente mediante um socorro a esse sistema por meio de recursos estatais?

No fundo nossa desavença reside na prática da filosofia. Se ela deixa de ser conhecimento do real ou crítica transcendental desse conhecimento, como acredito, ela não mais serve para legitimar uma forma de Estado, em particular a social-democracia, onde todos nós passamos a residir. Não há dúvida de que o pensamento filosófico tem enorme influência na política, mas, em geral, sistemas filosóficos servem para legitimar tanto o conservadorismo como o liberalismo mais radical.Creio ser mais producente examinar a prática política contemporânea para desenhar o mapa de suas tensões e de seus ideais. Hojeem dia todos queremos liberdade e igualdade, mas o significado desses 
conceitos-chave logo se embaralha quando passamos a discutir seu funcionamento. E nessa dispersão conflituosa vejo, antes de tudo, em plena vigência, as alienações do capital expostas na forma trinitária em que Marx as descreveu. Alienações, por sua vez, que já implicam a política na conquista de posições estratégicas nos mercados. "Os filósofos limitaram-se a interpretar o mundo de maneira diferente, cabe chegar a transformá-lo", se essa interpretação não é mais entendida como um conhecimento, a transformação passa a depender de uma luta que tem se mostrado mais eficaz quando não anula o ponto de vista do adversário. Por isso desconfio de uma política que imagine reformar o mundo a partir de um comitê central. Em suma, em vez de subestimar a política, aposto todas as minhas fichas na democracia, embora reconheça que a democracia de hoje seja uma calamidade.

Marcos teve a gentileza de deixar na sombra a diferença radical que nos separa. Se me lê pensando no que posso contribuir para a Teoria Crítica, desde logo descarta minha aposta fundamental. É sintomático que Certa herança marxista não é mencionado. Sou teimoso e ainda creio ser possível uma crítica da modernidade na base de uma análise do capital, ou melhor, do modo de produção capitalista. Mas o modelo do trabalho não está superado? Não é preciso voltar-se para uma crítica da razão? As objeções contra a razão posta em função de fins dados me parecem fora de foco, porquanto não discutem o próprio conceito de razão. Em contrapartida, se o modo de produção, como lembra Marx,éum silogismo, parece-me interessante examinar como essa produção, e não o ato de trabalho, é originariamente logos e ação coletiva. Daí meu interesse pela noção de jogo de linguagem e minhas tentativas de examinar a gramática do capital, da arte, da moral e da política. Mas sobre esse resto vale o silêncio.

JOSÉ ARTHUR GIANNOTTI é professor emérito do departamento de filosofia da FFLCH-USP e pesquisador do Cebrap.

Recebido para publicação em 21 de junho de 2011.

\section{NOVOS ESTUDOS}

CEBRAP

90 , julho 2011

pp. $57-62$ 